\title{
Spark Plasma Sintering of Highly Transparent Hydroxyapatite Ceramics
}

\author{
Byung-Nam KIM ${ }^{1}$, Naohiro HORIUCHI ${ }^{2}$, Apurv DASH${ }^{3}$, Young-Wook KIM ${ }^{4}$, \\ Koji MORITA ${ }^{1}$, Hidehiro YOSHIDA ${ }^{1}$, Ji-Guang LI $^{1}$ and Yoshio SAKKA ${ }^{1}$ \\ ${ }^{1}$ National Institute for Materials Science, 1-2-1 Sengen, Tsukuba 305-0047, Japan. \\ ${ }^{2}$ Tokyo Medical and Dental University, 2-3-10 Kanda-Surugadai, Tokyo 101-0062, Japan. \\ ${ }^{3}$ Katholieke Universiteit, Kasteelpark Arenberg 44, BE-3001 Leuven, Belgium. \\ ${ }^{4}$ University of Seoul, 163 Seoulsiripdae-ro, Dongdaemun-gu, Seoul 02504, Korea.
}

Received June 20, 2017; Revised July 24, 2017; Accepted July 31, 2017

\begin{abstract}
Highly transparent hydroxyapatite ceramics were fabricated by using the electrically conductive SiC mold during spark plasma sintering. Compared to the conventional graphite mold, the $\mathrm{SiC}$ mold lowered the sintering temperature by $50^{\circ} \mathrm{C}$ at least. The in-line transmission of the sintered ceramics is $82 \%$ at a wavelength of $600 \mathrm{~nm}$. The high transmission is a result of fine and dense microstructures. The light scattering behavior was examined to show the Rayleigh and Mie scattering at low and high wavelengths, respectively. The appearance of the Rayleigh scattering, which is caused by nano-sized pores, indicates that the Mie scattering by anisotropic grains was sufficiently suppressed by the fine microstructures.
\end{abstract}

\section{KEY WORDS}

hydroxyapatite, spark plasma sintering, transmission, scattering, grain size

\section{Introduction}

Hydroxyapatite (HA), $\mathrm{Ca}_{10}\left(\mathrm{PO}_{4}\right)_{6}(\mathrm{OH})_{2}$, is the main inorganic component of bone and tooth minerals. HA can adhere directly to hard tissues, such as bone and teeth, as well as to soft tissues, such as skin and muscular tissues, without the formation of intermediate layer. Porous HA is commonly applied to orthopedic and dental implant coatings, bone scaffolds and bone cements ${ }^{1)}$. Moreover, HA has excellent osteoconductive properties, which enable rapid bone fixation through rapid integration of material. Despite the excellent biomedical properties, however, dense bulk HA ceramics are rarely used owing to the inferior mechanical properties of low strength and low impact resistance. To enhance the mechanical properties of dense HA ceramics, a microstructure consisting of fine grains and low residual pores is required after sintering ${ }^{2}$.

Fine grains and low porosities in HA ceramics also indicate low light scattering and high transparency. For birefringent materials, such as HA and alumina, grains and pores act as a particle disturbing light propagation ${ }^{3,4)}$. Particularly, light scattering is remarkable for the particles which size is comparable to a wavelength of light, called Mie scattering. Smaller the grain size and lower the porosity, higher the transmission of HA ceramics. Transparent HA ceramics with fine and dense microstructures have

\footnotetext{
* Corresponding author, E-mail: kim.byung-nam@nims.go.jp
}

been achieved through hot isostatic pressing (HIP $)^{5-7)}$, microwave sintering ${ }^{8)}$ and spark plasma sintering (SPS ${ }^{2,9-13)}$. Transparent HA ceramics allows the direct observation of living cells. In our previous study, transparent HA ceramics with nano-sized grains and low light absorption were sintered through SPS ${ }^{2}$.

SPS is an efficient method to consolidate ceramics at low temperatures in a short time. The low sintering temperatures in SPS, compared to other sintering techniques, are certainly related to the electric field applied for heating. The electric field may enhance the densification by accelerating diffusion ${ }^{14,15)}$, suppressing grain growth ${ }^{16)}$ or softening particle surfaces ${ }^{17)}$. Though the exact mechanism is unclear, it was proven experimentally that the application of electric field contributes to lower the sintering temperature by enhancing densification ${ }^{18-20)}$. Recently, it was shown that the sintering temperature can also be lowered by using electrically conductive $\mathrm{SiC}$ as a mold material ${ }^{21)}$. Compared to the conventional graphite mold, the $\mathrm{SiC}$ mold enhanced densification and lowered the sintering temperature of transparent alumina by about $150^{\circ} \mathrm{C}$. In this study, by using the $\mathrm{SiC}$ mold, we fabricated highly transparent HA ceramics and analyzed the light scattering behavior.

\section{Experiments}

Two kinds of HA powder were used: commercial (HA-100, Taihei Chemical, Japan) and laboratory-made HA powder (LM-HA). 
The LM-HA was synthesized by a wet method from calcium hydroxide and phosphoric acid ${ }^{22)}$. An aqueous solution of phosphoric acid was dropped into a slurry of calcium hydroxide with stirring. The volume ratio was $1: 2$, to obtain the $\mathrm{Ca} / \mathrm{P}$ ratio equal to 1.67 . The obtained precipitate was filtered, dried at $60^{\circ} \mathrm{C}$ and then calcined at $800^{\circ} \mathrm{C}$ for $2 \mathrm{~h}$. A feature of HA-100 and LM-HA powder is shown in Fig. 1. HA-100 has typically a size of $20 \mathrm{~nm}$ in diameter and 60 100 nm in length, and LM-HA has a size of $60 \mathrm{~nm}$ in diameter and 120 150 nm in length. For LM-HA, the calcination at $800^{\circ} \mathrm{C}$ caused the larger particle size and the partial necking between particles.

The HA powder was poured into the electrically conductive $\mathrm{SiC}$ mold with a dimension of $28 \mathrm{~mm}$ in height and 9/28 $\mathrm{mm}$ in inner/ outer diameter. The $\mathrm{SiC}$ mold was heated directly to $820 \sim 880^{\circ} \mathrm{C}$ at a heating rate of $10^{\circ} \mathrm{C} / \mathrm{min}$ under a uniaxial pressure of $80 \mathrm{MPa}$ using a spark plasma sintering machine (LABOX315, Sinterland, Japan). Heating was conducted using a sequence consisting of DC pulses for $40 \mathrm{~ms}$ followed by zero current for $20 \mathrm{~ms}$. After holding for $20 \mathrm{~min}$ at the sintering temperature, the $\mathrm{SiC}$ mold was cooled down at $10^{\circ} \mathrm{C} / \mathrm{min}$ and the applied load was released gradually. Finally, a sintered disk was obtained with a diameter of $9 \mathrm{~mm}$ and a thickness of $3 \mathrm{~mm}$. During the running of SPS, the vacuum level was kept below $10^{-3}$ torr. The temperature was measured using a thermocouple in the non-through hole $(2 \mathrm{~mm}$ in diameter and $4 \mathrm{~mm}$ in depth) of the $\mathrm{SiC}$ mold. The $\mathrm{SiC}$ mold was covered with a carbon felt to reduce the heat dissipation, and a carbon paper of $0.2 \mathrm{~mm}$ thickness was inserted between the powder and the mold, in order to prevent a damage of the mold. Details of the SiC mold are described elsewhere ${ }^{21,23)}$.

For the measurement of optical properties, the sintered body was ground to a thickness of about $2.2 \mathrm{~mm}$ and carefully mirror-polished on both sides using a diamond slurry. The in-line transmission and total forward transmission were measured in a wavelength range of 240 1400 nm using a double-beam spectrophotometer (SolidSpec-3700DUV, Shimadzu, Japan) equipped with an integrating sphere. The distance between the sample and the detector is about $55 \mathrm{~cm}$. The measurement of the in-line transmission was conducted by inserting a mask with a $2-\mathrm{mm}$ diameter aperture in front of the detector in order to allow the detection of the specularly transmitted portion of the incident light beam with a 4-mm diameter. Since the aperture diameter $(2 \mathrm{~mm})$ of the mask is smaller than the beam diameter $(4 \mathrm{~mm})$, only the light with a scattering angle less than $0.3^{\circ}$ is detected.

For the sample polished and thermally etched at $750^{\circ} \mathrm{C}$, microstructural observation was conducted using a scanning electron microscope (SEM) (JSM-6500, JEOL, Japan). The grain size was measured by obtaining the average cross section area per grain and by assuming spherical grains. The measured grain size is an apparent one, so that it was multiplied by 1.225 to determine the true grain size $\mathrm{e}^{24)}$. The microstructure was also examined using a transmission electron microscope (TEM) (JEOL-2010 F, JEOL). For the TEM observation, a thin sheet with a thickness of $500 \mu \mathrm{m}$ was formed using a low-speed diamond cutter, mechanically polished to a thickness of $100 \mu \mathrm{m}$ and further thinned by an Ar ion-milling machine. The TEM was mainly used to confirm the existence of intragranular nano-sized pores that are not detected by the SEM observation.

\section{Results and Discussion}

\subsection{Microstructure}

The sintering with the SiC mold yielded fully densified HA ceramics with fine grains. Fig. 2 shows the microstructure of the HA ceramics sintered at $850^{\circ} \mathrm{C}$, where no significant pores are observed. The average grain size is $106 \mathrm{~nm}$ for HA-100, and $120 \mathrm{~nm}$ for LM-HA. Despite the large difference in the initial particle size (Fig. 1), the grain size after full densification is similar for the two HA ceramics. For LM-HA, the powder had been calcined at $800^{\circ} \mathrm{C}$ and was sintered at around $850^{\circ} \mathrm{C}$. Owing to the small temperature difference, the grain growth during sintering is not remarkable, as can be seen in Figs. 1 (b) and 2 (b). For HA-100, however, the nano-sized particles grew remarkably to a size of $106 \mathrm{~nm}$, similar to that of LM-HA. This observation indicates that though the nano-sized particles grow at a high rate initially during sintering,
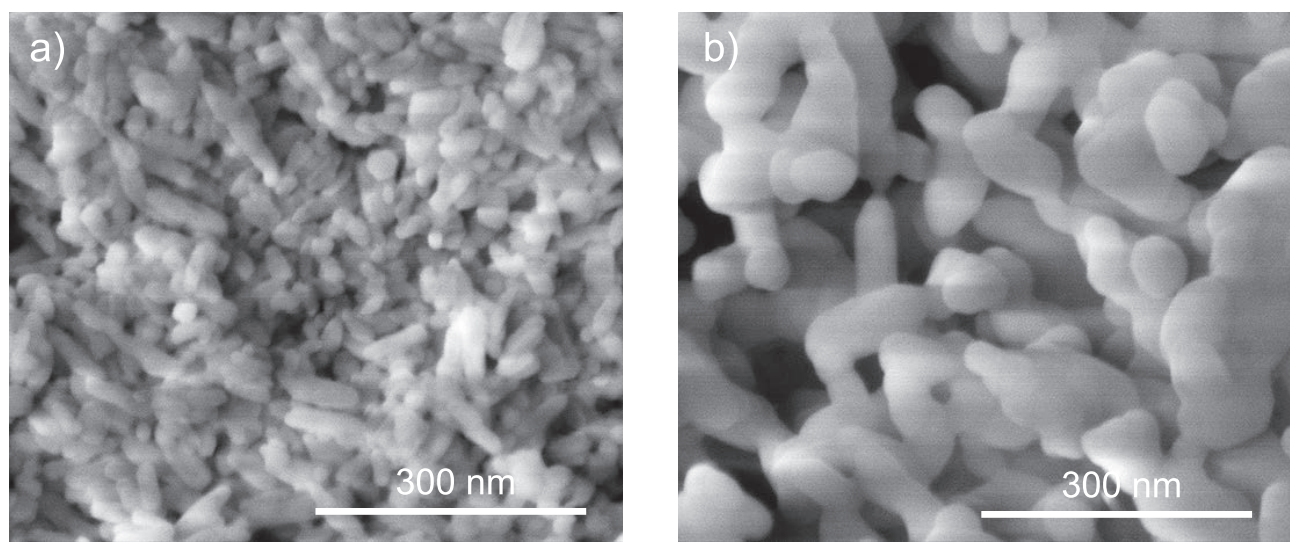

Fig. 1 Morphology of the used HA powder: (a) HA-100 and (b) LM-HA. 

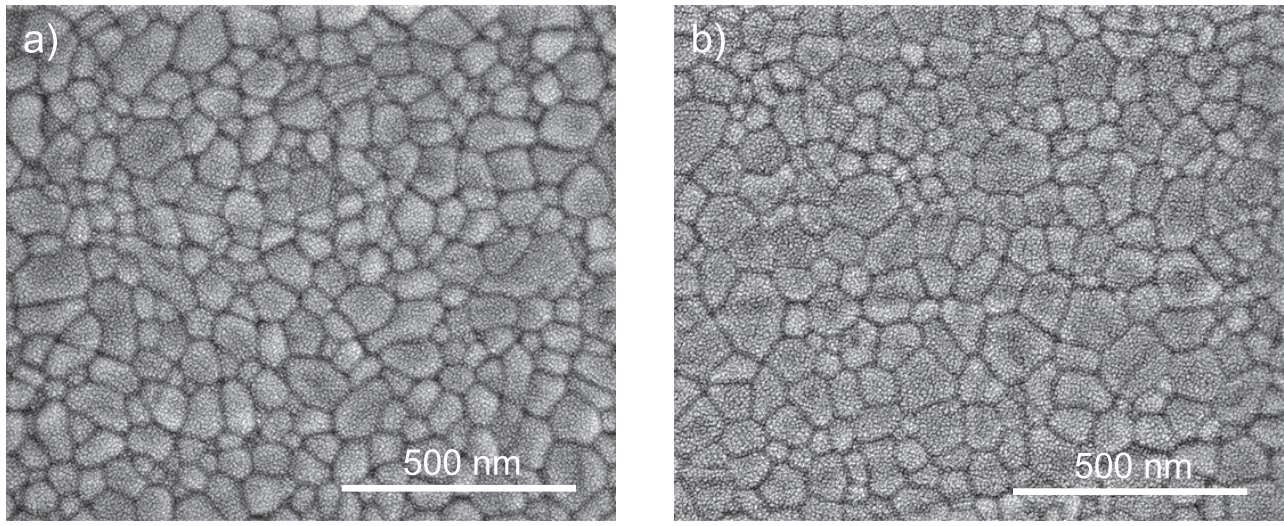

Fig. 2 Microstructure of the HA ceramics sintered at $850^{\circ} \mathrm{C}$ with (a) HA-100 and (b) LM-HA.

the growth rate seems to decrease rapidly at about $>100 \mathrm{~nm}$.

For LM-HA, it is noteworthy that the elongated particles (Fig. 1 (b)) were densified to form equiaxed grains (Fig. 2 (b)) without significant growth. The densification of powder without grain growth may occur by the deformation of powder or by active dislocations. Although diffusion is the most important mechanism during densification of ceramics, active dislocations also play a role in densification. Morita et al. ${ }^{25)}$ observed that the densification of $\mathrm{MgAl}_{2} \mathrm{O}_{4}$ occurs by active dislocations during SPS. Yoshida et al. ${ }^{26)}$ also observed that the deformation of HA ceramics at high temperatures is deeply related to the dislocation activity. Thus, the change in the particle/grain shape without significant growth for LM-HA can be explained by the dislocation activity during sintering.

\subsection{Light transmission}

The sintering with the $\mathrm{SiC}$ mold yielded fully densified transparent HA ceramics at $\geq 850^{\circ} \mathrm{C}$ for HA- 100 and at $\geq 820^{\circ} \mathrm{C}$ for LM-HA. At the sintering temperature of $820^{\circ} \mathrm{C}$, opaque HA ceramics were obtained for HA-100, whereas transparent ceramics for LM-HA. In our previous study for HA-100 with a graphite mold, transparent body was sintered at $\geq 900^{\circ} \mathrm{C}^{2)}$. By using the $\mathrm{SiC}$ mold, the sintering temperature for $\mathrm{HA}-100$ was lowered by $50^{\circ} \mathrm{C}$ at least.

Fine particles of powder enhance the densification rate so as to lower the sintering temperature. Usual nano-sized particles, however, are heavily agglomerated, which disturb the full densification by forming closed pores at low relative densities. This is the reason why it is difficult to sinter fully densified transparent ceramics with a grain size of $<100 \mathrm{~nm}$. In order to obtain such ceramics, nano-sized particles should be sufficiently de-agglomerated before sintering, and/or high pressures ( $>1 \mathrm{GPa}$ ) are required during sintering. In this study, the nano-sized particles of HA-100 were sintered without the treatment of de-agglomeration under the normal pressure of $80 \mathrm{MPa}$. As a result, despite the nano-sized characteristics, the sintering temperature for HA-100 is similar to that for larger particles of LM-HA.

In both HA ceramics, the in-line transmission shows a maximum for the sintering at $850^{\circ} \mathrm{C}$. At above $850^{\circ} \mathrm{C}$, the in-line transmission decreases gradually with an increase in the sintering temperature,

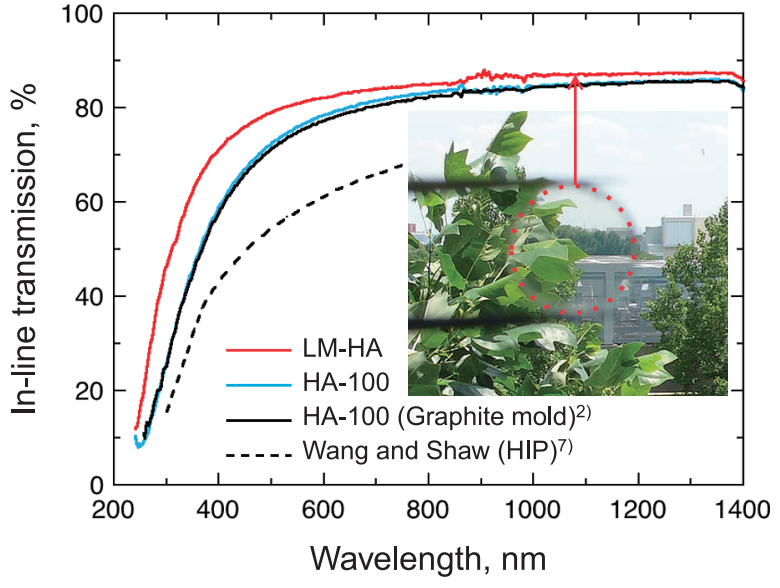

Fig. 3 In-line transmission of the HA ceramics sintered at $850^{\circ} \mathrm{C}$ by using the $\mathrm{SiC}$ mold. The transmission is normalized for a thickness of $1 \mathrm{~mm}$. The $2.2 \mathrm{~mm}$ thick HA ceramics (LM-HA) is shown in the inset, where the edge of the sample is represented by a dotted line.

mainly due to grain and pore growth. The in-line transmission for the sintering at $850^{\circ} \mathrm{C}$ is shown in Fig. 3, where the LM-HA ceramics show higher transmission. For a thickness of $1 \mathrm{~mm}$, the in-line transmission is $71 \%$ at $400 \mathrm{~nm}, 82 \%$ at $600 \mathrm{~nm}$ and $85 \%$ at $800 \mathrm{~nm}$. A theoretical transmission of HA is about $89 \%$ in the visible wavelengths. To our knowledge, the present in-line transmission for LM-HA is the highest among the values reported so far. Though several glass-like HA ceramics were reported ${ }^{5,6)}$, their in-line transmissions are not known. The highly transparent LM-HA ceramics show a glass-like appearance, as shown in the inset of Fig. 3. For HA-100, the in-line transmission of the HA ceramics sintered at $850^{\circ} \mathrm{C}$ with the $\mathrm{SiC}$ mold is almost similar to that of the ceramics sintered at $1000^{\circ} \mathrm{C}$ with a graphite mold, but is lower than that for LM-HA.

Fig. 4 represents the total forward transmission of the HA ceramics sintered at $850^{\circ} \mathrm{C}$. For LM-HA, the transmission is 79,86 and $88 \%$ at 400,600 and $800 \mathrm{~nm}$, respectively. Compared to the theoretical transmission, the present one is lower by less than $1 \%$ at $>800 \mathrm{~nm}$, and is comparable to that of $\mathrm{Li}$ and $\mathrm{Khor}^{13}$. Their HA ceramics, however, were sintered at higher temperatures $\left(1100^{\circ} \mathrm{C}\right)$, 


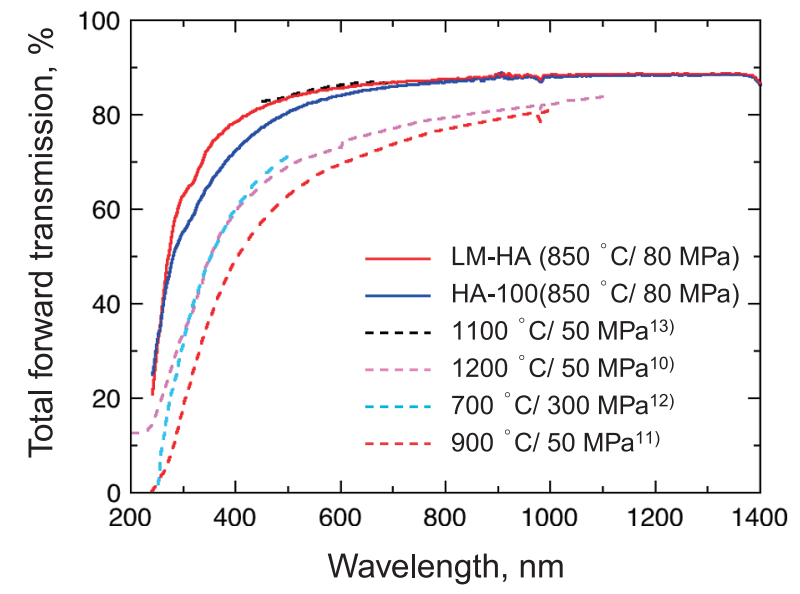

Fig. 4 Total forward transmission of the HA ceramics sintered at $850^{\circ} \mathrm{C}$. The transmission is normalized for a thickness of $1 \mathrm{~mm}$.

so that the grain size $(>411 \mathrm{~nm})$ is considerably larger than that of the present one $(120 \mathrm{~nm})$. Though the total forward transmission for the HA ceramics of Li and Khor ${ }^{13)}$ is comparable to the present transmission, their in-line transmission would be lower than our results due to the larger grains. The HA-100 ceramics show slightly lower transmission than the LM-HA ceramics in the visible wavelengths, but at $>800 \mathrm{~nm}$, show the transmission (>88\%) almost identical to that of LM-HA.

\subsection{Light scattering}

In transparent ceramics of cubic structure, light scattering occurs mainly by pores. For birefringent materials of non-cubic structure, large grains comparable to the wavelength also cause light scattering in addition to pores. HA is a birefringent material, with a refractive index of 1.651 and 1.644 for the ordinary and extraordinary ray, respectively. Owing to the slight difference $(0.007)$ in the refractive indices, HA ceramics with fine and dense microstructures become transparent, as in $\mathrm{Al}_{2} \mathrm{O}_{3}$. At fixed porosity, the light scattering decreases with decreasing grain size. In order to understand a nature of the light scattering for the present HA ceramics, the relationship between the scattering coefficient and the grain size was examined.

The scattering coefficient $\gamma_{\text {sca }}$ can be obtained experimentally from the relationship between the in-line transmission $T_{\text {in }}$ and the total forward transmission $T_{\text {tot }}$

$$
T_{\text {in }}=T_{\text {tot }} \exp \left(-\gamma_{\text {sca }} t\right)
$$

where $t$ is the sample thickness. $\gamma_{\text {sca }}$ can be calculated according to a theory of Mie scattering and Rayleigh scattering for large $(\pi d n>>\lambda)$ and small particles $(\pi d n<<\lambda)$, respectively, where $d$ is the particle size, $n$ is the refractive index of medium and $\lambda$ is the wavelength of the incident light ${ }^{3}$. For HA ceramics, there are two typical scattering sources: pores and grains. When the scattering occurs by anisotropic grains (Mie scattering), Apetz and Bruggen ${ }^{15}$ obtained $\gamma_{\text {sca }}$ by using the Rayleigh-Gans-Debye theory as

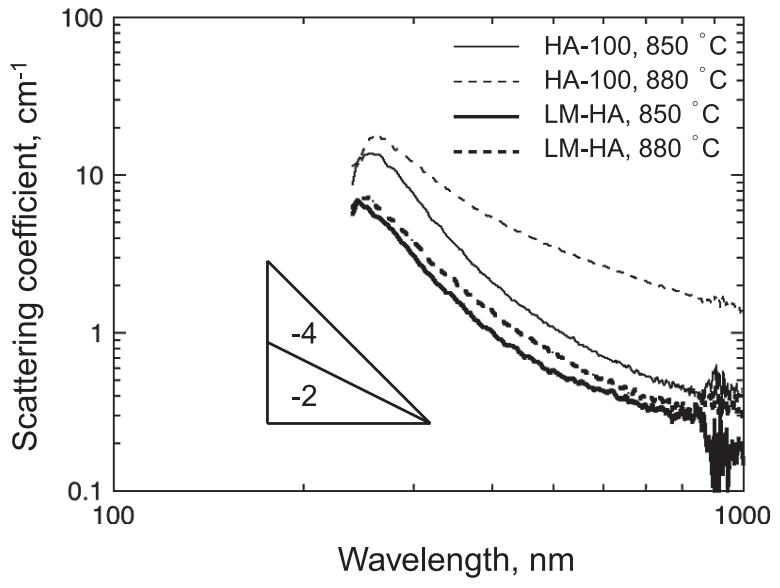

Fig. 5 Scattering coefficient of the HA ceramics sintered at $850^{\circ} \mathrm{C}$ and $880^{\circ} \mathrm{C}$.

$$
\gamma_{\mathrm{sca}}=\frac{3 \pi^{2} d \Delta n^{2}}{\lambda^{2}} V_{\mathrm{f}}
$$

where $\Delta n$ is a difference in the refractive indices and $V_{\mathrm{f}}$ is the volume density of the scattering particles. In $\mathrm{Al}_{2} \mathrm{O}_{3}$ ceramics, the scattering behavior could be explained well by Eq. $(2)^{27)}$. For various grain sizes $(0.25 \sim 10 \mu \mathrm{m}), \gamma_{\text {sca }}$ was proportional to $\lambda^{-2}$ in a wavelength range $(\lambda / d)$ of $0.2 \sim 2.0$, indicating the light scattering by anisotropic grains or the Mie scattering.

The scattering coefficient $\gamma_{\text {sca }}$ for the present HA ceramics is shown in Fig. 5. In the wavelength range examined, $\gamma_{\text {sca }}$ for LM-HA is lower than that for HA-100. The lower $\gamma_{\text {sca }}$ in spite of larger grain sizes can be attributed to lower porosities. Although the porosity was not measured, the higher in-line transmission for LM-HA in Fig. 3 indicates lower porosities. And the scattering coefficient $\gamma_{\text {sca }}$ increases with an increase in the sintering temperature, because of grain and pore growth.

In Fig. 5, the slope between $\gamma_{\text {sca }}$ and $\lambda$ at $>400 \mathrm{~nm}$ is -2 for both HA ceramics, indicating that the scattering behavior at $>400 \mathrm{~nm}$ can be explained by the Mie scattering of Eq. (2). However, the slope increases with a decrease in the wavelength, and approaches -4 for both HA ceramics. A slope of -4 at $250 \sim 400 \mathrm{~nm}$ cannot be explained by the Mie scattering. Then, we can consider the other typical scattering source: pores. In Figs. 3 5, it is found that most light scattering occurs at low wavelengths $(<400 \mathrm{~nm})$, which may occur by fine pores. Fig. 6 represents the nano-sized pores observed in the LM-HA ceramics. Several studies also reported the nanosized pores remaining after SPS of ceramics ${ }^{28,29)}$, including the HA100 ceramics $^{30)}$. The typical size is $5 \sim 30 \mathrm{~nm}$, which satisfies the size condition of Rayleigh scattering $(\pi d n<<\lambda)$.

For Rayleigh scattering, $\gamma_{\text {sca }}$ can be represented theoretically as ${ }^{3)}$

$$
\gamma_{\mathrm{sca}}=\frac{16 \pi^{4} d^{3} \Delta n^{2} n^{2}}{9 \lambda^{4}} V_{\mathrm{f}}
$$

where $\gamma_{\text {sca }}$ is proportional to $\lambda^{-4}$. A slope of -4 between $\gamma_{\text {sca }}$ and $\lambda$ at 


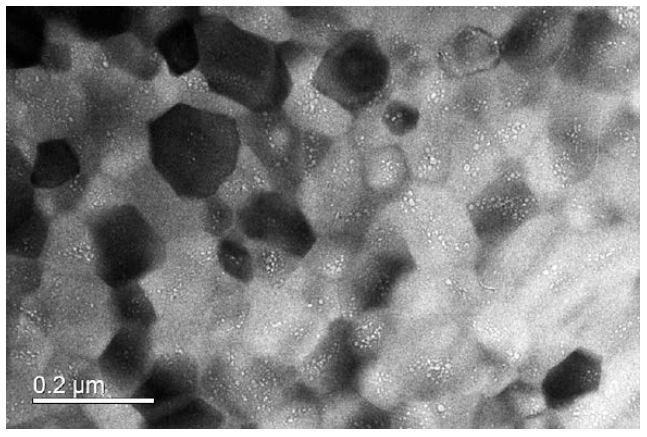

Fig. 6 Nano-sized pores in the HA ceramics of LM-HA sintered at $850^{\circ} \mathrm{C}$.

250 400 nm in Fig. 5 is well consistent with a relationship of Eq. (3). Hence, it is concluded that the scattering at $\lambda<400 \mathrm{~nm}$ in the HA ceramics was caused by nano-sized pores. $\gamma_{\text {sca }}$ for the Rayleigh scattering of Eq. (3) decreases rapidly with increasing $\lambda$, and at $\lambda$ $>400 \mathrm{~nm}$, seems to be much lower than $\gamma_{\text {sca }}$ for the Mie scattering of Eq. (2). At $\lambda>400 \mathrm{~nm}$, the light scattering is dominated by the Mie scattering. The Mie scattering decreases with decreasing grain size, as shown in Eq. (2). For nano-sized grains, the Mie scattering would be further decreased, and then the Rayleigh scattering only would appear for entire visible wavelengths, which enhance the transparency. For nano-sized grains after sintering, it is expected that the birefringency of HA ceramics becomes no more significant in light transmission.

\section{Conclusions}

Highly transparent HA ceramics with fine and dense microstructures could be obtained at $850^{\circ} \mathrm{C}$ by SPS using the $\mathrm{SiC}$ mold. Compared to the conventional graphite mold, the $\mathrm{SiC}$ mold lowered the sintering temperature by $50^{\circ} \mathrm{C}$ at least. The measured in-line transmission is the highest among the values reported so far. The examination of the scattering coefficient shows that major light scattering occurred by the nano-sized pores at $\lambda<400 \mathrm{~nm}$ and by the anisotropic grains at $\lambda>400 \mathrm{~nm}$. The scattering phenomena can well be explained by a theory of Rayleigh and Mie scattering.

\section{References}

1) S. V. Dorozhkin: Biomaterials, 31 (2010) 1465-1485.

2) B. -N. Kim, E. Prajatelistia, Y. -H. Han, H. -W. Son, Y. Sakka, S. Kim: Scripta Mater., 69 (2013) 366-369.

3) H. C. van de Hulst: Light scattering by small particles, Dover (1981) 85-130.

4) R. Apetz, M. P. B. van Bruggen: J. Am. Ceram. Soc., 86 (2003) 480-486

5) K. Ioku, M. Yoshimura, S. Somiya: J. Ceram. Soc. Jpn., 96 (1988) 109-110.

6) K. Uematsu, M. Takagi, T. Honda, N. Uchida, K. Saito: J. Am. Ceram. Soc., 72 (1989) 1476-1478.
7) J. Wang, L. Shaw: Scripta Mater., 63 (2010) 593-596.

8) Y. Fang, D. K. Agrawal, D. M. Roy, R. Roy: Mater. Lett., 23 (1995) 147-151.

9) K. Ioku, D. Kawagoe, H. Toya, H. Fujimori, S. Goto, K. Ishida, A. Mikuni, H. Mae: Trans. Mater. Res. Soc. Jpn., 27 (2002) 447-449.

10) Y. Watanabe, T. Ikoma, A. Monkawa, Y. Suetsugu, H. Yamada, J. Tanaka, Y. Moriyoshi: J. Am. Ceram. Soc., 88 (2005) 243-245.

11) A. A. Gandhi, R. D. Gunning, K. M. Ryan, S. A. M. Tofail: J. Am. Ceram. Soc., 93 (2010) 3773-3777.

12) M. Eriksson, Y. Liu, J. Hu, L. Gao, M. Nygren, Z. Shen: J. Euro. Ceram. Soc., 31 (2011) 1533-1540.

13) Z. Li, K. A. Khor: Key Eng. Mater., 631 (2015) 51-56.

14) A. V. Nenashev, F. Jansson, S. D. Baranovskii, R. Osterbacka, A. V. Dvurechenskii, F. Gebhard: Phys. Rev. B, 81 (2010) 115203

15) V. Gill, P. R. Guduru, B. W. Sheldon: Int. J. Solids Struct., 45 (2008) 943-958.

16) S. Ghosh, A. H. Chokshi, P. Lee, R. Raj: J. Am. Ceram. Soc., 92 (2009) 1856-1859.

17) R. Chaim: Mater. Sci. Eng. A, 443 (2007) 25-32.

18) D. Yang, R. Raj, H. Conrad: J. Am. Ceram. Soc., 93 (2010) 2935-2937.

19) M. Cologna, B. Rashkova, R. Raj: J. Am. Ceram. Soc., 93 (2010) 3556-3559.

20) H. Yoshida, K. Morita, B. -N. Kim, Y. Sakka, T. Yamamoto: Acta Mater., 106 (2016) 344-352.

21) B. -N. Kim, A. Dash, Y. -W. Kim, K. Morita, H. Yoshida, J. -G. Li, Y. Sakka: J. Ceram. Soc. Jpn., 124 (2016) 1141-1145.

22) N. Horiuchi, N. Wada, K. Nozaki, M. Nakamura, A. Nagai, K. Yamashita: J. Appl. Phys., 119 (2016) 084903.

23) Y. -W. Kim, K. J. Kim, H. C. Kim, N. -H. Cho, K. -Y. Lim: J. Am. Ceram. Soc., 94 (2011) 991-993.

24) R. Apetz, M. P. B. van Bruggen: J. Am. Ceram. Soc., 86 (2003) 480-486.

25) K. Morita, B. -N. Kim, H. Yoshida, K. Hiraga: Scripta Mater., 63 (2010) 565-568.

26) H. Yoshida, B. -N. Kim, H. -W. Son, Y. -H. Han, S. Kim: Scripta Mater., 69 (2013) 155-158.

27) B. -N. Kim, K. Hiraga, K. Morita, H. Yoshida, Y. Kagawa: Acta Mater., 58 (2010) 4527-4535.

28) B. -N. Kim, K. Hiraga, K. Morita, H. Yoshida, T. Miyazaki, Y. Kagawa: Acta Mater., 57 (2009) 1319-1326.

29) R. Marder, R. Chaim, C. Estournes: Mater. Sci. Eng. A, 527 (2010) 1577-1585.

30) J. Yun, B. N. Kim, Y. H. Han, H. W. Son, S. Kim, H. Yoshida: Adv. Appl. Ceram., 114 (2015) 175-177. 